\title{
Genetics of schizophrenia
}

SIR-As is his wont, Steven Rose (Nature 336, 512; 1988) belittles the efforts of molecular biologists to understand human problems. Rose's objection that "Sherrington et al. have not shown that [the locus on chromosome 5 to which their RFLP markers are linked] is sufficient [for a person to develop schizophrenia] - a prerequisite for useful genetic counselling - is misleading on two points. First, Sherrington et al. (Nature 336, 164-167; 1988) did not claim that they had found a locus which inevitably leads to schizophrenia. They specifically quote a penetrance of 85 per cent even given a broad definition of schizophrenia-related diseases, stating that there are influences at work other than the genetic ones they have identified. Second, the locus is useful for genetic counselling whether or not it determines schizophrenia in the way that Rose would require of it. Genetic counselling has for many years relied on statistical arguments, often stemming only from mendelian genetics, with no linked markers at all. Many couples have felt that to be told that their children have a 25 per cent change of suffering from (say) cystic fibrosis is better than knowing nothing. Even with the advent of more statistically certain markers, such as the G8 probe which is linked to the locus causing Huntington's chorea, it is clearly recognized that possession of the locus is quite compatible with survival to 70 years of age with intact mental faculties. As always, genetic counselling is not only genetics - it is also counselling on the interpretation of those genetics.

This is exactly the reverse of the reductionism that Rose so vividly describes, but which is not actually present in your original articles: it is placing human interpretation on molecular results. That Rose invokes this argument only to knock it down as counter to a human science is at least consistent with itself, if not with the

\section{Antarctic hero}

SIR-I was appalled to see (Nature 336, 417 ; 1988) that your Sydney, Australia, correspondent or your typesetter, or both, managed to spell the name of one of Australia's heroes as Sir Douglas Lawson rather than Sir Douglas Mawson. Any geologist who has ever handled a stromatolite knows his name (that includes me) and anyone with even the most meagre knowledge of Antarctic exploration is well aware of his exploits (that includes his great-grandniece, to whom I am married).

Paul I. Abell

Department of Chemistry,

Pastore Chemical Laboratory,

University of Rhode Island,

Kingston, Rhode Island 02881-0801, USA facts. That he then uses it to argue against attempts to develop more carefully targeted drugs to treat incapacitating mental disease is obtuse. Of course this course has not been successful in the past. It has not been available in the past. On this argument we would still be treating schizophrenia with the ducking chair and the stake.

\section{PA Technology,}

William Bains

Melbourn

Royston,

Herts SG8 6DP, UK

\section{Reprints justified}

SIR-I agree with Ivor Smith (Nature 336, $708 ; 1988)$ that sending reprints is costly and time-consuming. In places such as Italy however, photocopiers abound, but university libraries do not subscribe to major journals, or journals are distributed only after months of delay. In such cases, it is vital for investigators to receive reprints (or even cheap photocopies) of papers within a few weeks of their listing in Current Contents or similar indexes.

Marco Ruggiero

Istituto di Patologia Generale,

University of Firenze,

Italy

SIR-I request reprints because it saves time. I subscribe to Current Contents and, on average, request three or four reprints per week, which takes about half an hour. If I were to go to the library, find the journals and copy the articles, it would probably take at least half a day. And often the journals that I need are not in the library because of budget cuts.

I feel that an investigator has the obligation not only to do research but also to disseminate it. Most administrators would probably be glad to provide the cost of photocopying and postage to have research at their institution known and cited.

1420 McCain Lane 244

Manhattan, Kansas 66502, USA

\section{Swiss academic strife}

SIR-The picture drawn by John Maddox (Nature 336, 333; 1988) of Swiss academic life is in my opinion a bit too rosy. I agree that there are a few positive aspects: faculty salaries, particularly those of senior professors, are high; retirement benefits are generous; SNFS research grants are easily obtainable. On the other hand, I do not share the view of ample opportunity for research. Minimum teaching loads for faculty at the University of Zurich, for example, are eight hours a week; an excessive amount of time is spent at ad hoc committee, departmental, faculty and senate meetings, occasionally lasting past midnight; and a similar amount of time is spent in exchanges with hordes of administrators at all kinds of levels of the education ministry of the canton.

As noted by Steven Dickman on the same page, student/faculty ratios are extremely biased in some fields. Even more crucial, it seems to me, is that as a by-product of a lax or non-existent admission policy, the range in quality of students is also extreme. This, in combination with the large number of students, has led to a decline in the quality of research and teaching, approaching mediocrity at best in some departments.

The bending of rules by cantonal officials to allow foreign academics to buy housing without having lived in Switzerland for five years is certainly a nice gesture. By contrast, once arrived in the land of Alps, foreign academics are often treated as second-class fellows by their Swiss colleagues. I believe there may be an analogy here to the treatment of women as secondclass citizens in Swiss society. In 1984, Frau Elisabeth Kopp was elected by her parliamentary colleagues into the executive branch of the federal government, a first in Swiss history. How about the faculty of one or the other Swiss university electing one of their foreign colleagues to a deanship or even a chancellorship? Recently, Kopp was forced to resign from her cabinet post. I hope that is where the analogy would break down.

WALTER LEUTENEGger

Department of Anthropology,

University of Wisconsin,

Madison, Wisconsin 53706, USA

\section{Obfuscation}

SIR-The recent letter by C. A. Smith et al. (Nature 337, 181-84; 1989) seems to be an example of the apoptotic misuse of the Greek language. As before with other Greek words, I was unable to establish an unambiguous meaning of apoptosis. $\alpha \pi \sigma \pi \tau \omega \sigma \omega$ is translated in the standard Greek-German dictionary as verirren (to go astray), so apoptotic might then be aberrant, and apoptosis could be translated by aberration. Using these meanings in the article, however, I was led astray: apoptosis as a process related to T lymphocytes, apoptotic as characteristic of these cells remained meaningless. The authors, however, seemed to like the word. But for a broad understanding of the article it is misleading. I am afraid that such use of cryptic Greek language by British scientists is a way of establishing barriers between them and others - deliberately, I wonder?

Grieshalde 11, Bernhard KLEINE

D-7417 Pfullingen, FRG 